\title{
Epidemiological analysis of 22 patients with congenital bleeding diathesis hospitalized in the Department of Maxillofacial Surgery in Lublin, Poland, 2008-2013
}

\author{
Jolanta Wojciechowicz', Anna Gawęda', Patryk Kasprzak', Bożena Sokołowska², \\ Tomasz Tomaszewski ${ }^{1}$ \\ ${ }^{1}$ Maxillofacial Surgery Department, Medical University, Lublin, Poland \\ 2 Haematooncology Department, Medical University, Lublin, Poland
}

Wojciechowicz J, Gawęda A, Kasprzak P, Sokołowska B, Tomaszewski T. Epidemiological analysis of 22 patients with congenital bleeding diathesis hospitalized in the Department of Maxillofacial Surgery in Lublin, Poland, 2008-2013. J Pre-Clin Clin Res. 2016; 10(1): 45-49. doi: $10.5604 / 18982395.1208188$

\begin{abstract}
Introduction. Haemophilia A and B are congenital bleeding disorders caused by coagulation factor VIII or IX deficiency. Haemophilia $A$ and $B$ occur in men, like all qualities dependent on genes linked to gender, whereas women are asymptomatic carriers of the gene. The most dangerous manifestations of severe haemophilia include spontaneous haemorrhages into the joints, muscles and body cavities, haematuria and potentially very dangerous intracranial haemorrhages are also quite frequent. The most common manifestations in the region of the maxillofacial skeleton and oral cavity are recurring bleedings from the nose and the gums after dental extractions, as well as extensive haemorrhages from wounds after surgical procedures.

Objective. The aim of the study was the analysis of epidemiologic case records of 22 patients affected by various types of haemophilia, admitted to Maxillofacial Surgery Department at Medical University in Lublin, Poland, during 2008-2013.

Results. The most numerous group constituted patients diagnosed with Haemophilia A, followed by patients with von Willebrand disease and Haemophilia B, aged 21-40 years. The main cause of hospital admission was the need to perform complex oral cavity sanation. The patients were treated with factor VIII or Factor IX, FEIBA or Heamate P, depending on the type and severity of bleeding diathesis.
\end{abstract}

\section{Key words}

haemophilia, replacement therapy, oral cavity surgeries

\section{INTRODUCTION}

Haemophilia A (HA) and B (HB) are congenital bleeding diathesis caused by inhibition of coagulation factor VIII (FVIII) or IX (FIX). Haemophilia A and B occur in men occur in men, like all qualities dependant on genes and sexrelated, while women are asymptomatic carriers $[1,2,3]$. Haemophilia A is diagnosed in 1 out of 5,000 male infants and haemophilia B is diagnosed in 1 out of 30,000 male infants $[2,4,5]$. Prevalence of Haemophilia A and B in Poland is estimated at 1:12300 inhabitants. In $30-50 \%$ of patients, mutation occurs spontaneously and there is no family history of the disease [5]. Since the clinical features of haemophilia $A$ and $B$ do not differ, the diagnosis is based on the deficient coagulation factor activity in plasma. There are three types of haemophilia: severe, moderate and mild: severe form where the factor level is less than $1 \%$ of normal $(<0.01 \mathrm{IU} / \mathrm{ml})$; moderate form - where the factor level is $1-5 \%$ of normal (0.01-0.05 IU/ml); mild form - with the factor level more than $5-40 \%$ of normal $(>0.05-040 \mathrm{IM} / \mathrm{ml})[4]$.

The most dangerous manifestations of severe haemophilia include spontaneous bleeding into the joints, muscles and body cavities, haemorrhages into the joints, hematuria and menacing intracranial haemorrhages which are also

Address for correspondence: Jolanta Wojciechowicz, Maxillofacial Surgery Department, Medical University of Lublin, Staszica 11, 20-081 Lublin, Poland E-mail: lanyfztk@wp.pl

Received: 08 June 2015; accepted: 09 February 2016 quite frequent $[1,3,5]$. Bleedings that result from injuries or surgeries performed without the proper haemostatic protection. The diagnosis of haemophilia should include determining FVIII or FIX deficiency level in plasma, as well as identification of the causative mutation. Currently performed genetic tests detect the carrier state with $95 \%$ accuracy. The treatment of haemophilia encompasses increasing the activity of the deficient coagulation factor in blood circulation to stop or prevent active bleeding [3, $5,7]$. The following medications are currently used in the prophylaxis and treatment of haemophilia:

a) LyophilizedFVIII or FIX concentrate derived from plasma (plasma-derived concentrates), or recombinant concentrate produced in the genetic engineering processes (recombinant concentrates).

b) 1-deamino-8-D-arginine vasopressin (DDAVP) desmopressin.

c) Medicines that inhibit fibrinolysis (antifibrinolytics) [1, $2,4,5]$.

Since intravenous infusions of 1 unit of FVIII per $1 \mathrm{Kg}$ of body mass increase FVIII activity in plasma by approximately $2 \%$, the following formula is used to estimate the proper dosage of FVIII: Dosage (units) = desired increase in FVIII activity in the patient's plasma (\%) $\mathrm{x}$ body mass BM $(\mathrm{kg}) \mathrm{x}$ 0.5. Intravenous injections of FIX result in an increase of FIX activity in the patient's plasma by $1 \%$. The following formula is used: Dosage (units) = desired increase in FIX activity in the 
patient's plasma (\%) x body mass BM (kg). The injections are repeated every 12,18 or 24 hours, depending on the clinical situation $[2,5]$. Desmopressin derivates from antiduretic hormone and stimulates FVIII and von Willebrand factor (VWF) secretion which are stored in angio-endothelium to plasma. Endothelium storages of FVIII and VWF are depleted within 3-7 days and further administration of the medicine is no longer justified. Administering desmopressin is not advisable in children and patients over 60 years old due to hyponatraemia, headache and vomiting. DDAVP is administered as $0.3 \mu \mathrm{g} / \mathrm{kg}$ body mass diluted in intravenous infusion lasting at least 30 minutes $[2,4,5]$. There are medicines in the form of nasal inhalation in 150-300 $\mu \mathrm{g}$ dosage, unfortunately they have not yet been registered in Poland. Antifibronolitics are very useful in stopping mucous bleeds in the oral and nasal cavities and alimentary system. There are two synthetic analogues of lisine which stop fibrinolysis and stabilize the blood clot: aminocaproic acid (EACA) and the more potent trannexanic acid (TA), the former in the dosage of $50-60 \mathrm{mg} / \mathrm{kg} / \mathrm{BM}$ every $4-6$ hours, the latter in the dosage of $10-15 \mathrm{mg} / \mathrm{kg}$ every $8-12$ hours. Contraindications to administer EACA and TA include haematuria, renal failure, severe embolic and thrombotic processes, and colour vision dysfunction [2, 4, 5]. Other adjunct medicines are haemostatic agents used locally, such as: absorbable gelatin sponge, dehydrated cellulose, regenerated and hydrated cellulose, microfibrinous collagen, fibrin glue and thrombin, lamina gel [4]. These agents support the coagulation process by creating a scaffolding for the blood clot and exerting light mechanical pressure on the wound. Effective prevention of spontaneous bleeding into the joints and muscles, bleeds during the perioperative period, as well as severe diathesis episodes, should be the superior aim in the treatment of severe haemophilia $[1,2,3,8]$.

Patients affected by haemophilia should be treated in Comprehensive Care Haemophilia Centres with access to laboratory facilities and coagulation concentrates by a multispecialist medical team, including not only haematologists but also orthopedists, paediatricians, infectious disease specialists, geneticists, stomatologists and psychologists. Every patient with congenital bleeding diathesis possesses an identification card with the description of the type of disorder and recommended haemostatic medicines. The patients should also keep a record of bleeding episodes and concentrate infusions $[1,2,5,9,10]$.

Factor VIII and IX inhibitor is a crucial problem in the case of dental procedures in patients with haemophilia $1,2,4]$. FVIII inhibitor occurs in about $30 \%$ of patients with severe haemophilia A and in $0.9-7 \%$ of patients with moderate and mild haemophilia whereas FIX inhibitor occurs in 1.5\% - $3 \%$ of patients with haemophilia $\mathrm{B}$. The patients require homeostatic treatment called 'by-passing therapies' [2, 4, 6]. In such cases, rFVIIa (recombinant activated factor VII), FEIBA (activated prothrombin complex concentrate), TA are used $[2,3]$. The presence of inhibitor makes replacement treatment of bleeds more difficult or even impossible and leads to severe anaphylactic reactions [3]. Treatment of complicated haemophilia with inhibitors is aimed at eliminating inhibitor and stopping bleeding.

Acquired haemophilia A. This is a different type of haemorrhage diathesis caused by autoantibodies that inhibit the coagulation function of FVIII. Both men and women affected by the disease, and although the cause of the disease is identical, because in congenital haemophilia the clinical manifestations are different [2]. Diffuse subcutaneous bruises, mucosal haemorrhages, bleedings from surgical and dental extraction wounds, as well as diffuse and painful intramuscular hematomas, can be observed in acquired haemophilia. The annual incidence of acquired haemophilia is about $0.2-1$ person per million inhabitants. The disease usually affects patients in the $6^{\text {th }}-7^{\text {th }}$ decade of their lives [2]. Patients with coexisting autoimmune diseases, such as systemic lupus erythematosus, rheumatoid arthritis (RA) and ulcerative enteritis, constitute quite a significant percentage of patients (20\%). The most crucial medicines administered in patients affected by acquired haemophilia are activated prothrombin complex concentrate and recombinant active factor VII. The dosage of aPCC (activated prothrombin complex concentrate) and rFVIIa (recombinant activated factor VII) is identical to that in classical inhibitor complicated haemophilia $[2,6]$. Imuno-supressives are used to eliminate antibodies to FVIII. Oral dosage of prednison is $1 \mathrm{mg} / \mathrm{kg}$ in monotherapy or combined with cyclophosphamide (CTX) in a daily dosage of 100-150 mg [2]. In patients affected by acquired haemophilia, APTT (activated partial thromboplastin time) is prolonged (2-3 times), with normal values of prothrombin, thrombin and bleeding time and correct number of plates and fibrinogen value [2]. Von Willebrand disease (VWD) has a prevalence of approximately $0.1 \%$ of the population, and is caused by deficiency or impairment of von Willebrand factor (VWF) glikoprotein synthesised in angio-endothelium cells. There are three types of severity of von Willebrand disease, of which the most common manifestations include recurrent nose bleeds, mucosal haemorrhages and bleedings from skin wounds, and long-term and profuse menorrhea [2, 4]. Dental extractions and surgeries performed without haemostatic treatment usually result in profuse bleeding. Currently, two medicines: DDAVP and lyophilized concentrates of factor VIIIwith VWF, are used in the treatment of bleedings in VWD patients. Antifibrinolyticsare is very useful in mucosal haemorrhages treatment $[2,4]$.

\section{OBJECTIVE}

The aim of the study is retrospective analysis of treatment procedures performed in 22 patients with various types of haemophilia admitted to the Maxillofacial Surgery Department at the Medical University in Lublin, Poland, during 2008-2013.

\section{MATERIALS AND METHOD}

The subjects of the study were haemophilic patients admitted to the Maxillofacial Surgery Department at Medical University in Lublin, Poland, during 2008-2013. The reasons for hospital admission - patients' age, coexisting diseases, surgical procedures performed and replacement therapy patterns - were analysed. Statistica 10.0 PL software and Excell spreadsheets were used. 


\section{RESULTS}

A total of 22 patients with diagnosed congenital haemorrhagic diathesis were treated at the Maxillofacial Surgery Department. The most numerous group were patients with Haemophilia A (15 patients), followed by patients with von Willebrand disease (5 patients), and finally, 2 patients with Haemophilia B.

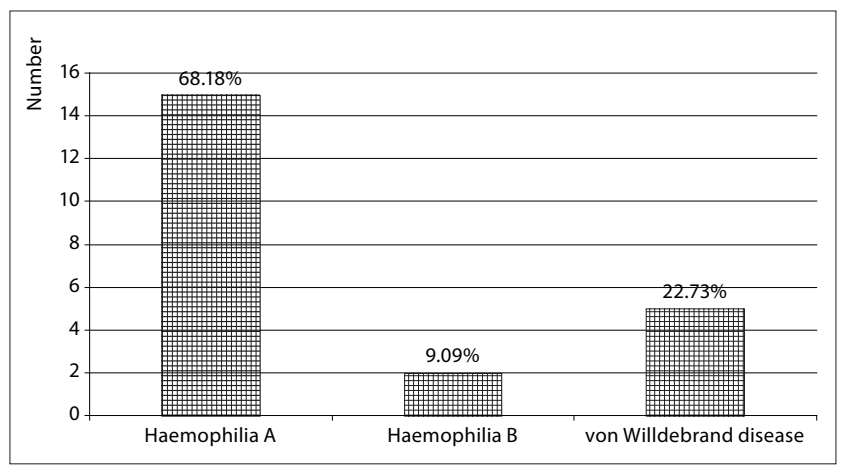

Figure 1. Types of blood diathesis in patients in the study

The largest group consisted of patients diagnosed with Haemophilia A (15 persons), with von Willebrand disease - 5 people, and 2 people diagnosed with Haemophilia B.

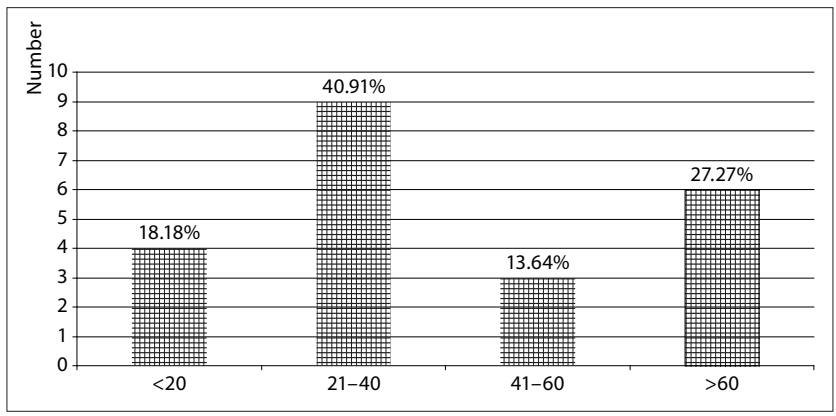

Figure 2. Age groups of patients in the study

The most numerous group were patients with blood diathesis aged $21-40$ years $(40.91 \%$ of all patients admitted to hospital). The second group were patients aged over 60 $(27.27 \%)$, whereas the least numerous group were patients aged $41-60$ years $(13.64 \%)$.

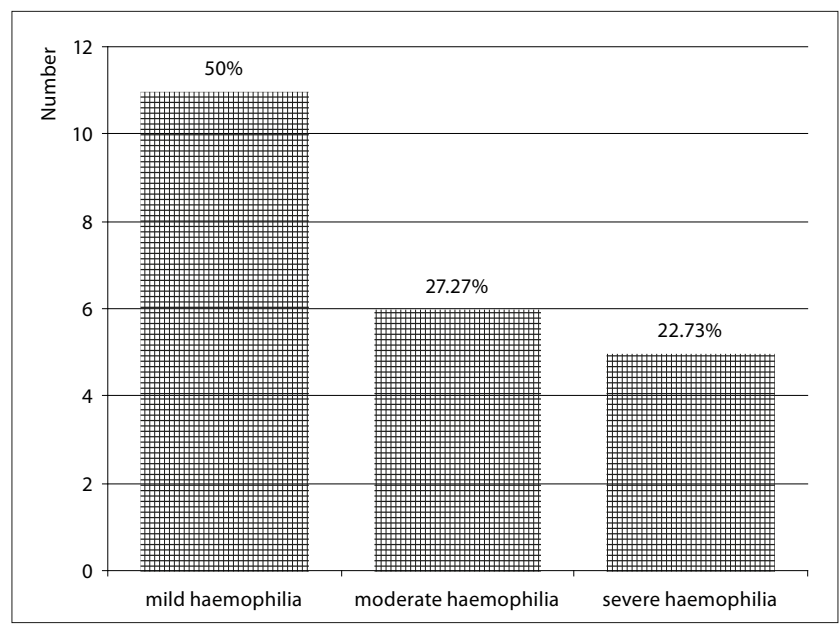

Figure 3. Severity of blood diathesis in patients in the study
Patients with the mild type of haemophilia (50\%) dominated. Moderate type of haemophilia was diagnosed in $27.27 \%$ of patients, whereas $22.73 \%$ of patients were affected by severe haemophilia.

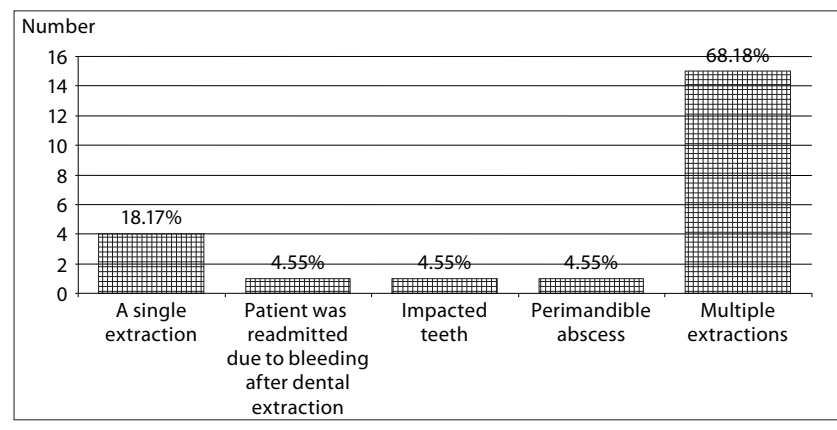

Figure 4. Reasons for hospital admissions of patients with congenital blood diathesis

The main reason for hospital admission was necessity to perform multiple extractions - in 15 cases (68.18\%). The remaining reasons included a single tooth extraction that required prompt surgical interventions, impacted teeth and teeth-related inflammations - abscesses. The scope of treatment provided depended on the reason for hospital admission and the patient's general health. The second cause of treatment were single extractions and surgical treatment of sockets after dental extraction. In the remaining cases, impacted teeth surgical exposure and tooth-related abscess incisions were performed.

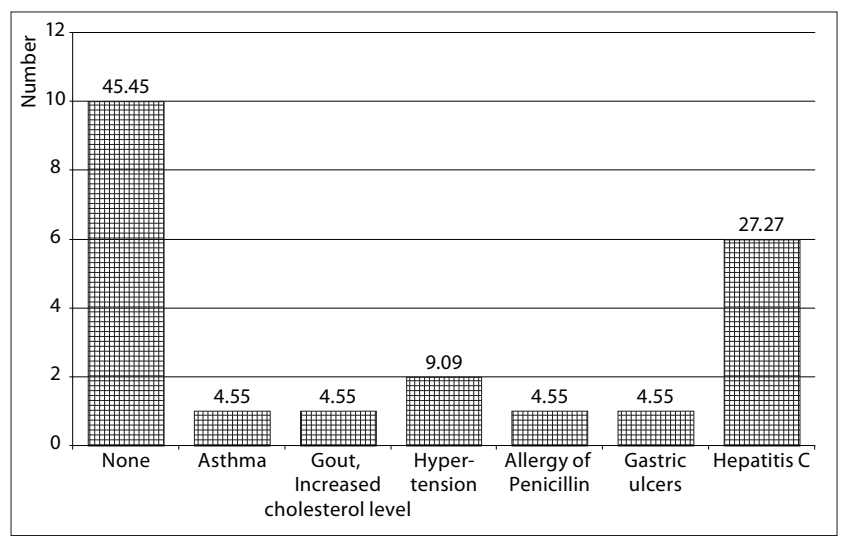

Figure 5. Coexisting diseases in patients with congenital blood diathesis

Coexisting diseases are the major problem in patients admitted to hospital, with hepatitis C (27.27\%) as one of the leading ones. Patients also reported hypertension, gastric ulcers, asthma, gout and allergy (Fig. 6).

The average duration of hospitalization for patients with mild haemophilia was 4.09 days, for patients with moderate haemophilia - 5 days, and for patients with severe diathesis - 5.4 days (Fig. 7 ).

From the above diagram it may be concluded that only in the case of mild haemophilia could surgery be performed without coagulation factor replacement therapy. Complementary intravenous or oral treatment with Exacyl (tranexamic acid), subcutaneous, intravenous or nasal treatment with Minirin (desmopressin DDAVP), local surgical wound dressing with gelatine sponge Gelfoam or Surgical - plantderived haemostatic - $100 \%$ oxidised regenerated, were used. The majority of patients admitted to hospital required 


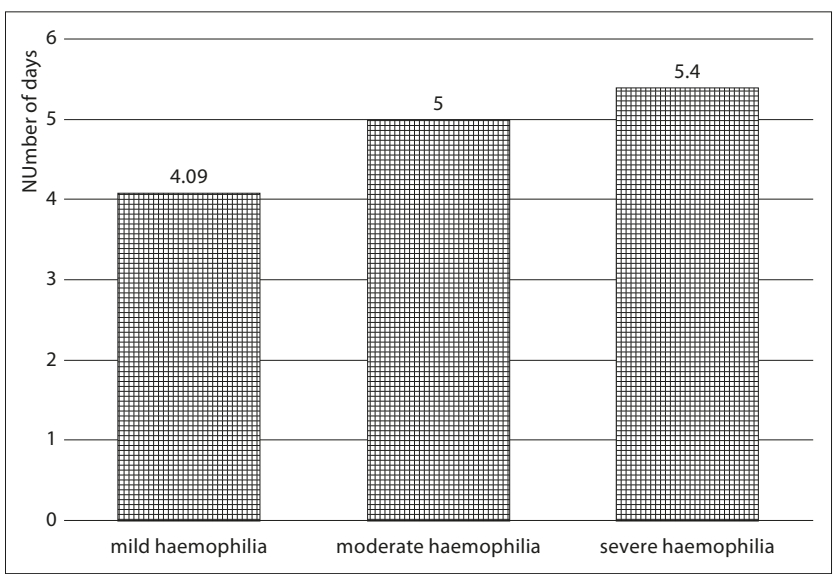

Figure 6. Average duration of hospitalization and severity of congenital blood diathesis

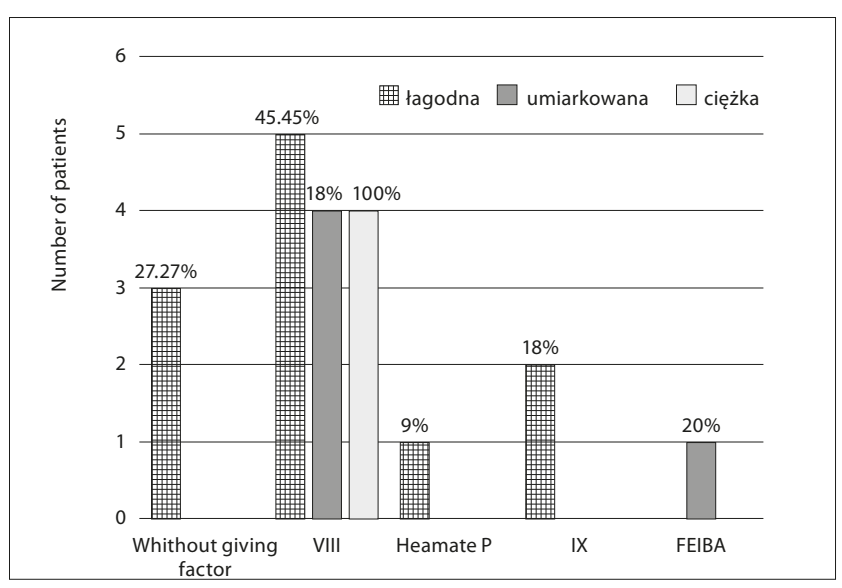

Figure 7. Dependence of type of administered factor on the severity of haemophilia

simultaneous replacement and maintenance treatment both before and after surgeries. Factor VIII or IX, FEIBA or Heamate $\mathrm{P}$ (von Willebrand factor and coagulation factor VIII in combination) were administered according to the type and severity of blood diathesis. There was no need to administer coagulation factors in $27.27 \%$ of mild cases of blood disorders. Administration of factor VIII was necessary before and after surgeries in 4 severe haemophilia patients, and 4 of moderate haemophilia patients. FEIBA was administered in $20 \%$ of patients (1 case).

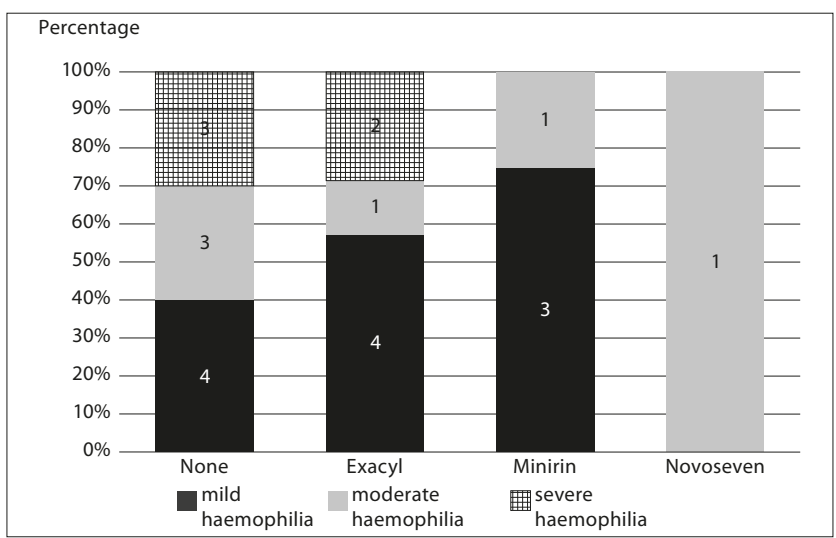

Figure 8. Drugs that increase blood clotting administered in parallel with substitution treatment, and the severity ofa hemophilia
The most often used adjuvant drug that increased blood clotting is Minirin (desmopressin DDAVP) in 3 patients and Exacyl(tranexamic acid) in 4 patiens, mainly in mild haemophilia and less commonly in the moderate form of haemophilia.

\section{DISCUSSION}

Patients affected by congenital blood disorders have significantly lowered quality of life due to the problem of bleeding. Relatively simple dental procedures require proper preparation and post-operative management.

Treatment planning should involve liaison between the dental team and haemophilia care centres $[10,11]$. According to Salem and Eshghi, maintaining restrictive oral hygiene that reduces the need for invasive dental procedures, as well as education concerning prophylaxis against dental caries and other oral diseases, are essential factors which improve the quality of life in all people, and especially children with coagulation disorders [9]. Nowadays, owing to high-purity coagulation factor concentrates, dental procedures can be performed in ambulatory care conditions. Anderson advises that in the case of lyophilized factor VIII or IX concentrates, dental procedures should be performed when the factor level varies from 30-50\%; however, he points out that some European haemophilia care centres recommend a factor level ranging $60-80 \%$ [4]. Nevertheless, in properly treated patients with mild haemophilia, dental procedures that encompass bleeding can be performed in all dental surgeries on the condition that adjunct medications, such as Desmopressin (Minirin) or TA (Exacyl) that inhibit fibrinolysis, are administered. In the presented study, in $27.27 \%$ of hospitalized patients with mild haemophilia, it was not necessary to administer coagulation factors, only replacement therapy with the above- mentioned preparations was used.

Haemophilia A with inhibitors to factor VIII is a major therapeutic problem. It requires treatment with FEIBA (activated prothrombin complex concentrateAPCC in a dosage of $50-100 \mu \mathrm{g} / \mathrm{kg}$ BM body mass), or rFVIIa (recombinant active factor VII in a dosage of 70$90 \mu \mathrm{g} / \mathrm{kg} /$ body mass BM), and local haemostatic measures [ 1 , $4,12]$. The future of haemophilia treatment is with PEGylated liposomes, which were used to synthesise factor VIII of prolonged efficacy $[1,6]$. Research has shown that the efficacy of PEGylated liposomes is twice longer than classic factors which may enable reduction of the frequency of coagulation factors administration in the future. This has a key impact on the treatment of children since the number of intravenous punctures performed to administer factors is reduced, and the patients' quality of life is improved.

In the 1960s, the main method of invasive dental treatment were procedures performed under general anaesthesia and transfusions of blood derivative preparations with coagulation factors. Having compared the above-dissertation with the study by Wojciechowich et al. [13], undertaken from 1981-2007, one can observe that several significant differences arise in the course of time, as well as advances in haemophilia treatment. The total number of patients with bleeding disorders admitted to the Maxillofacial Surgery Department in Lublin has definitely decreased, but patients affected by Haemophilia A still comprise the most numerous 
group (154 patients in 1981-2007 and 15 patients in 20072013). Until 2007, cryoprecipitate and fresh frozen plasma were mainly used in replacement therapies. In 1991, factor VIII and IX concentrates appeared, and currently they are the standard treatment. The type of medical provision is another difference that can be observed. Owing to the National Bleeding Disorders Care Programmes (Haemophilia Care Centres), which also provide dental prophylaxis in patients up to the age of 18 years, oral hygiene has improved. However, in 1981-2007, the great majority of patients in the Maxillofacial Surgery Department in Lublin were children who required single or multiple deciduous tooth extractions, or were admitted due to profuse bleeding during primary or secondary dentition. From 2008-2013, no such cases were reported in the department and the greatest number of patients were aged 21-40 years and over the age of 60 (27.27\%). Currently, the average duration of hospital treatment has shortened from 1 to 3 days in $54.5 \%$ of patients, compared to the previous years.

The number of patients with acute inflammations, such as dental abscesses, has decreased (only 1 case between 2008-2013). The use of antifibrinolytics and desmopressin in bleeding prophylaxis in haemophilic patients, enables performing minor dental procedures in dental surgeries without implementing coagulation factor treatment [14, $15,16]$. Transfusion-transmitted infections are a problem that emerged with plasma-derived concentrates treatment, although the risk of contaminating HCV, HBV and HIV through coagulation factors currently used in Poland is close to zero [5]. Nevertheless, according to the analysis conducted in Polish patients with severe haemophilia A and B born before 1991, about $80 \%$ are infected with HCV and about $10 \%$ with HBV [2].

Since 1980s, all blood derivative preparations have been checked for the presence of virus $C$. The infection is primarily present in elderly patients who might have been administered preparations contaminated by virus $\mathrm{C}$ when they were not checked previously for their presence $[6,10,11]$. The analysis confirmed this dependence since hepatitis $C$ virus was diagnosed in $27.27 \%$ of hospitalized middle-aged and elderly patients.

The most recent change in the treatment of haemophilia which was introduced in Poland in 2008, involves prophylactic administration of factor VIII in all patients with severe haemophilia since birth in order to prevent haemophilic arthropathy caused by spontaneous haemorrhages into the joints. Moreover, ambulatory patients are given factor concentrate at home, and in the case of bleeding onset, they have the opportunity to infuse the preparation immediately [10].

\section{CONCLUSIONS}

1. The greatest percentage of haemophilic patients hospitalized in the Maxillofacial Surgery Department in Lublin during
2008-2013 comprised patients with mild haemophilia A, aged $21-40$ years.

2. The main reason for hospital admission was the need to perform multiple extractions of numerous gangrenous teeth.

3. Concomitant diseases include hepatitis C $(27.27 \%$ of hospitalized patients).

4. The average duration of hospitalization in more than half of the patients, mainly with mild haemophilia, was 1-3 days. The duration of hospitalization was longer in patients with severe haemophilia (up to 5.4 days).

5. Dental treatment planning should involve liaison between the dental team and a Haemophilia Care Centre.

\section{REFERENCES}

1. Knobe K, Berntorp E. New treatments in hemophilia: insights for the clinician. Ther Adv Hematol. 2012; 33: 165-175.

2. Windyga J. Haemophilias- advances in diagnosis and management. Acta Haematol Pol. 2010; 41(2): 183-199.

3. Windyga J, Solano M, Trujill, Hafeman A. BAX326 (RIXUBIS): a novel recombinant factor IX for the control and prevention of bleeding episodes in adults and children with hemophilia B. Ther Adv Hematol. 2014; 5(5): 168-180.

4. Anderson JAM, Brewer A, Creagh D, Hook S, Mainwaring J, McKenan A, Yee TT, Yeung CA. Guidance on the dental management of patients with haemophilia and congenital bleeding disorders. British Dental J. 2013; 215(10): 497-504.

5. Windyga J, Chojnowski K,Klukowska A, Łętowska M, Mital A, Podolak-Dawidziak M, Zdziarska J, Zawilska J. Polish guidelines for the management of inherited bleeding disorders caused by coagulation factor deficiency. Acta Haematol Pol. 2008; 39(3): 537-564.

6. Windyga J. How will haemophilia be treated in future? Acta Haematol Pol. 2008; 39(4): 651-660.

7. Israels S, Schwetz N, Boyar R, McNicol A. Bleeding Disorders: Characterization. Dental Considerations and Management. J Can Dent Assoc. 2006; 72: 9.

8. Van Bladel ER, Roest M, de Groot PG, Schutgens R. Up-regulation of platelet activation in hemophiliA. www.haematologica.org/ content/96/6/888, 2011; 96(6): 888-895.

9. Salem K, Eshghi P. Dental health and oral health-related quality of life in children with congenital bleeding disorders. Haemophilia. 2013; 19: $65-70$.

10. Ministerstwo Zdrowia. Narodowy program leczenia chorych na hemofilie i pokrewne skazy krwotoczne na lata 2012-2018. (in Polish).

11. Sumera A. Polskie Stowarzyszenie Chorych na Hemofilię. Biuletyn informacyjny 2012; 2(43). (In Polish)

12.Zanon E, Brandolin B, Saggiorato G, Bacci Ch. Complex dental extractions in a patient with severe haemophilia $\mathrm{A}$ and inhibitors treated with activated prothrombin complex concentrate. Blood Transfus. 2012; 10: 225-7.

13. Wojciechowicz J, Maślanko G, Dobieżańska B, Tomaszewski T. Therapeutic procedures of congenital haemorrhagic diathesis in patients hospitalised at the Maxillo-Facial Surgery Departament of Medical University of Lublin During 1981-2007. Pol J Environ Stud. 2008; 17, 6A, 1: 120-125.

14. Peisker A, Raschke G-F, Schultze-Mosgau S. Management of dental extraction in patients with Haemophilia A and B: A report of 58 extractions. Med Oral Patol Oral Cir Bucal. 2014; 1,19 (1): 55-60.

15. Gupta A, Epstein J, Cabay R. Bleeding Disorders of Importance in Dental Care and Related Patient Management. J Can Dental Assoc. 2007; 73(1).

16. Sokołowska B, Walter-Croneck A, Gromek T, Dmoszynska A. Acquired hemophilia and life- threatening bleeding -Difficult problem that affects not only males but also females. Acta Haematol Pol. 2011; 42(3): 583-591. 